\title{
Quantitative Assessment of Olfactory Experience during Pregnancy
}

\author{
Avery N. Gilbert, PhD and Charles J. Wysocki, PhD
}

\begin{abstract}
Results of the National Geographic Smell Survey were used to investigate the effects of pregnancy on olfactory perception and odor-related behavior. The responses to test odors and survey questions of 13,610 pregnant and 277228 nonpregnant U.S. women between 20 and 40 years of age were analyzed. In comparison to nonpregnant women, pregnant women rated their own sense of smell lower, more often rated the test odors less pleasant smelling, more often classified the test odors as inedible, were less likely to report odor-evoked memories, and used perfume and cologne less frequently. Differences in odor detection and intensity rating did not favor either group.
\end{abstract}

“...during both my pregnancies my sense of smell was so heightened that I found it astounding. I mentioned it to several doctors but none seemed interested nor could say why this was so. I feel my sense of smell is still more acute than before I became pregnant but nothing to compare with what I experienced during pregnancy and immediately after the births."

-32-year-old, Australia

"...my sense of smell during [pregnancy] was more keen than ever. I was very sensitive to unpleasant odors such as cigarette smoke and bleachso sensitive, in fact, that they made me feel like vomiting."

-35-year-old, U.S.

From Roure, Inc. Teaneck, New Jersey (A.N.G.) and the Monell Chemical Senses Center, Philadelphia, Pennsylvania (C.J.W.).

Address reprint requests to: Avery N. Gilbert, Ph.D., Roure, Inc., 1775 Windsor Road, Teaneck, N] 07666.

Received for publication January 21, 1991; revision received June 7, 1991.

Psychosomatic Medicine 53:693-700 (1991)

693

\section{INTRODUCTION}

Reports such as the two quoted above are familiar to medical personnel caring for pregnant women. A change in odor perception during pregnancy is a seemingly frequent event. As described anecdotally, it can appear as an increase in odor sensitivity, or in odor awareness, and sometimes as a decrease in these parameters. It can also manifest itself as a parosmia that alters the character of certain smells, typically making them unpleasant and aversive. Although physicians are familiar with these symptoms, the olfactory experience of pregnant women has seldom been the object of direct scientific inquiry, despite the relevance of odor quality to the development of nausea and there is little firm evidence on which to base medical judgments.

Given the fragmentary state of knowledge, there is a clear need for a quantitative assessment of olfactory perception in pregnancy. The National Geographic Smell Survey, conducted in September and October of 1986, provided an unprecedented opportunity to explore the topic (3). Accompanied by an article on the sense of smell, the survey reached a pofood aversions in pregnancy $(1,2)$. Thus, 


\section{A. N. GILBERT AND C. J. WYSOCKI}

tential audience of more than 10 million readers. A large number of women of childbearing age responded to a set of test odors, and to a number of demographic and behavioral questions. Reported here are findings that bear on the question of olfaction in pregnancy.

\section{METHODS}

The Smell Survey was inserted in each copy of the September 1986 issue of the National Geographic, and sent worldwide to 10.7 million members of the Society. A detailed description of the methodology (odorant concentrations and complete questionnaire) can be found in Ref. 4

Participants were asked their age and sex, and women were asked whether they were pregnant (yes or no). Other questions assessed physician-diagnosed allergies (to animals, food, pollen, drugs) and diseases (arthritis, hypertension, diabetes, ulcer). Participants rated their own sense of smell $(1=$ poor to $5=$ excellent). They also noted how often they used a cologne or perfüme (none, 1-2, 3-4 or 5-7 days per week), and whether they ever used it more than once a day (yes or no). If the subject had experienced a loss of smell, he or she was asked to identify the apparent cause (colds and flu. allergy, exposure to chemicals, head injury, pregnancy, or unknown).

The Smell Survey form contained six microencapsulated odorants chosen to represent a range of pleasantness, familiarity, and food-relatedness. The two food-related odors were isoamyl acetate, a banana- or pear-like fruity odor, and eugenol, a major constituent of clove oil. In the U.S. both are considered pleasant smelling. A pleasant and familiar nonfood odor was the floral sample of synthetic rose. An unpleasant non-food odor was provided by a mixture of mercaptans, sulphurous compounds added to natural gas as a warning odor. Galaxolide ${ }^{\circledR}$, a synthetic musk note widely used in commercial perfumery, was included in the Smell Survey and provided an odor rated mildly pleasant. Musky notes are often associated with mammalian scent gland secretions. A typical instance is the scent pod of the adult male musk deer which provides pharmacologically interesting material often used in traditional Oriental medicine (5). The final test item was the volatile steroid androstenone which is naturally produced in many mammals, including humans. It can be isolated from sweat and urine, more so from men's than women's. For some people Galaxolide and androstenone share a pleasant musky quality, but for others androstenone smells like unpleasant, stale urine. Despite the biological relevance of these two odors, 10 to $50 \%$ (depending on age) of the U.S. population is anosmic to each compound (6).

Participants were asked to scratch and sniff each odor panel and answer these questions: Did you smell something (yes or no)? How would you rate the quality of this odor (from $1=$ unpleasant to $5=$ pleasant)? How intense is the odor (from $1=$ weak to $5=$ strong)? Did the odor evoke a vivid memory (yes or no)? Would you eat something that smelled like this (yes, no, no opinion)? Would you apply something that smelled like this to your body (yes, no, no opinion)? Which word best describes this odor (no odor, floral, musky, urine, foul, ink, spicy, woody, fruity, burnt, sweet, other)?

A worldwide total of $1,420,000$ usable surveys were returned (a $13 \%$ response rate); $1,200,000$ were from the United States. The results presented here are based on all U.S. women $(N=290,838)$ aged 20 to 40 , of whom $13,610(4.7 \%)$ were pregnant. This age range accounted for $95 \%$ of all pregnant participants. Ages outside this range were not included due to small sample sizes among the pregnant group. The nonpregnant women were older than the pregnant women $(32.23 \pm 0.01$ SEM vs. $30.05 \pm 0.03$ years $)$. The majority $(94.9 \%)$ of the combined sample described their ethnicity as white.

Age-related effects on olfactory performance were evident in a previous analysis of U.S. respondents (4). Odor detection and ratings of intensity and pleasantness decline with advanced age; the rate of decline is odor-specific. Although age effects were not large in the range of the present sample. age was used as a covariate where appropriate to control for differences in the age structure of the pregnant and nonpregnant women.

\section{RESULTS AND DISCUSSION}

The Smell Survey results offer little evidence that pregnant and nonpregnant women differ in odor sensitivity. However, a clear difference was found in the percentage of respondents able to detect eugenol. It was detected more frequently 


\section{OLFACTION IN PREGNANCY}

by pregnant respondents, and the difference was evident across the age range (Fig. 1).

The perception of odor intensity varied significantly with pregnancy, but not in a readily interpretable manner. Intensity ratings were analyzed by ANOVA for each odorant (Table 1). Pregnant women found isoamyl acetate and mercaptans significantly more intense, and androstenone and Galaxolide less intense. (Inclusion of age, fragrance use, and selfrating as individual and simultaneous covariates did not change the outcome.) No overall pattern of pregnancy-related hypo- or hyper-responsivity emerged, but it remains possible that odor-specific changes in responsivity exist. There is an analogy in gustatory perception: pregnant women were less able to correctly identify concentration differences in salt solutions, but could do so with sucrose solutions (7).

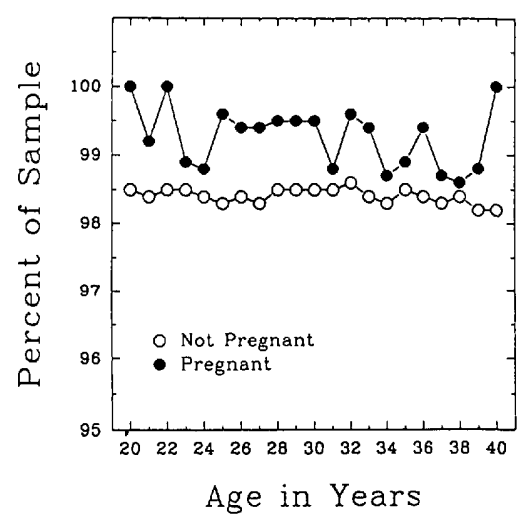

Fig. 1. Percentage of pregnant and nonpregnant women, ages 20 to 40 years, able to detect the eugenol odor.
The Smell Survey provides quantitative support to anecdotal observations that some odors become offensive during pregnancy. Hedonic ratings were analyzed by ANOVA for each odor (Table 1). Pregnant women rated three odors (Galaxolide, eugenol, and mercaptans) significantly less pleasant. Interestingly, pregnant women rated the musky/urinous smell of androstenone as more pleasant. Inclusion of age, fragrance use, and self-rating as individual and simultaneous covariates did not change the outcome. There was no consistent relationship between odor intensity and hedonic ratings; therefore, it is unlikely that the hedonic ratings were simply a reflection of relative odor strength.

Given the nausea and food aversion often associated with pregnancy, odorbased edibility ratings might be expected to show pregnancy-related changes. Only the two food-related odors were rated as edible (Table 2): isoamyl acetate (fruity, banana-like) and eugenol (spicy, clovelike). Yet the perceived edibility of five of the six test odors was lower among pregnant women (Table 2). This consistent response pattern may have been due to making the odor quality judgment a biologically relevant one, namely whether or not to ingest. Future research might uncover even greater differences in preference by using odors reported to be aversive to pregnant women, e.g., fish, potatoes or vegetables (8).

The edibility results were generally parallel to those for "wear-ability" (Table 2). Pregnant women were more willing than nonpregnant women to wear the scent of androstenone (musky/urinous); they were less likely to wear eugenol (spicy). However, while pregnant women found rose less edible, they were more willing to wear it. 
A. N. GILBERT AND C. J. WYSOCKI

To analyze pregnancy-related differences in matching a test odor to verbal descriptors (Table 3), a correct descriptor was defined as that chosen most frequently by respondents able to smell the odor. (For androstenone, either of the heavily endorsed descriptors "musky" or "urinous" were defined as correct.) Despite their lower self-assessments of smell ability (see below), pregnant women identified all but two test odors better than nonpregnant women. But pregnant women were less able to correctly identify androstenone and Galaxolide. One difference in each direction was statistically significant (Table 3). When identifying mercaptans, pregnant women outper-
TABLE 3. Correct Identification of Odor as a Function of Pregnancy Status ${ }^{a}$

\begin{tabular}{lcc}
\hline \multicolumn{1}{c}{ Odor } & Nonpregnant & Pregnant \\
\hline Androstenone & 28.7 & $27.2^{\star}$ \\
Isoamyl acetate & 53.4 & 53.9 \\
Galaxolide & 40.9 & 40.2 \\
Eugenol & 88.5 & 89.0 \\
Mercaptans & 60.9 & $64.2^{\star}$ \\
Rose & 90.3 & 90.8 \\
\hline
\end{tabular}

a Values are percentage of each group correctly identifying the odor.

${ }^{*}$ Chi-square tests on frequencies, $p<0.001$.

formed nonpregnant women across nearly the entire age range (Fig. 2).

Pregnant women applied perfume and cologne less frequently than nonpregnant

TABLE 1. Mean Odor Quality and Intensity as a Function of Pregnancy Status

\begin{tabular}{lccccc}
\hline \multirow{2}{*}{ Odor } & \multicolumn{2}{c}{ Quality $^{2}$} & & \multicolumn{2}{c}{ Intensity } \\
\cline { 2 - 3 } \cline { 5 - 6 } & Nonpregnant & Pregnant & & Nonpregnant & Pregnant \\
\hline Androstenone & 3.04 & $3.11^{\star}$ & & 2.34 & $2.27^{*}$ \\
Isoamyl acetate & 3.74 & 3.73 & & 4.07 & $4.09^{\star}$ \\
Galaxolide & 3.55 & $3.51^{*}$ & & 2.68 & $2.65^{\star \star}$ \\
Eugenol & 4.10 & $4.08^{\star \star}$ & & 4.43 & 4.44 \\
Mercaptans & 1.35 & $1.30^{\star \star}$ & & 4.35 & $4.38^{*}$ \\
Rose & 4.30 & 4.31 & & 4.35 & 4.35 \\
\hline
\end{tabular}

a Based on a five-point scale, with $1=$ unpleasant and $5=$ pleasant.

${ }^{b}$ Based on a five-point scale, with $1=$ weak and $5=$ strong.

* ANOVA, $p<0.01$; * ANOVA, $\rho<0.05$.

TABLE 2. Pregnancy Status and Whether the Respondent Would Eat or Wear the Odor ${ }^{\circ}$

\begin{tabular}{lccccc}
\hline \multirow{2}{*}{ Odor } & \multicolumn{2}{c}{ Would Eat It } & & \multicolumn{2}{c}{ Would Wear It } \\
\cline { 2 - 3 } \cline { 5 - 6 } & Nonpregnant & Pregnant & & Nonpregnant & Pregnant \\
\hline Androstenone & 6.3 & $6.8^{*}$ & & 36.1 & $38.7^{\star}$ \\
Isoamyl acetate & 62.1 & 61.6 & & 17.9 & 17.3 \\
Galaxolide & 4.9 & $4.3^{\star *}$ & & 51.5 & 50.8 \\
Eugenol & 65.1 & $63.2^{\star}$ & & 25.8 & $23.2^{\star}$ \\
Mercaptans & 1.1 & 1.0 & & 0.6 & 0.6 \\
Rose & 3.8 & $3.1^{*}$ & & 70.7 & $71.9^{* \star}$ \\
\hline
\end{tabular}

a Values are the percentage of each group answering affirmatively.

*Chi-square test, $p<0.01 ;{ }^{\star \star}$ chi-square test, $p<0.05$. 


\section{OLFACTION IN PREGNANCY}

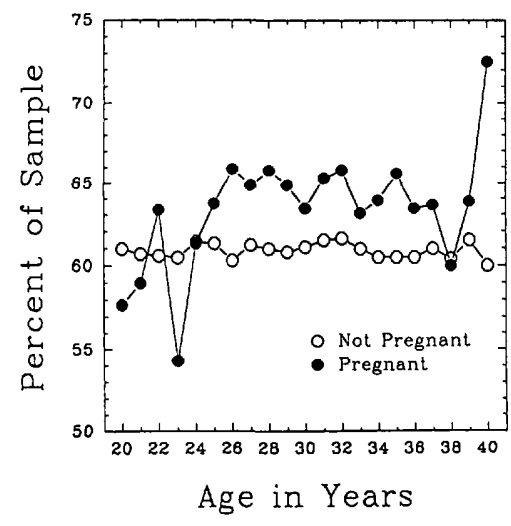

Fig. 2. Percentage of pregnant and nonpregnant women, ages 20 to 40 years, who chose the adjective "foul" to describe the odor of mercaptans.

women (Fig. 3). Modal use frequency was 1-2 days per week for pregnant women, and 5-7 days per week for nonpregnant women. The use of fragrance more than once a day was also substantially lower among pregnant $(32.1 \%)$ than nonpregnant women $(42.1 \%)$. The factors involved in reduced fragrance use by pregnant women remain to be identified. Among them may be 1) disuse due to olfactory insensitivity, 2) aversion due to hypersensitivity or parosmia, or 3) a change in selfperceived sexiness and social image with advance pregnancy. The structure of the Smell Survey does not permit one of these hypotheses to be singled out as more likely.

Pregnancy was associated with a significant reduction in the frequency of odorevoked memories for all test odors (Table 4). This unanticipated and unusual result merits further investigation. It may be related to attentional factors in odor perception.

Pregnancy was significantly associated with lower self-rated smell ability (chisquare $=40.13, d f=4, p<0.0001$ ) (Table $5)$. In comparison to nonpregnant women, fewer pregnant women rated themselves "excellent" (category 5), while more placed themselves one rating lower (cat-

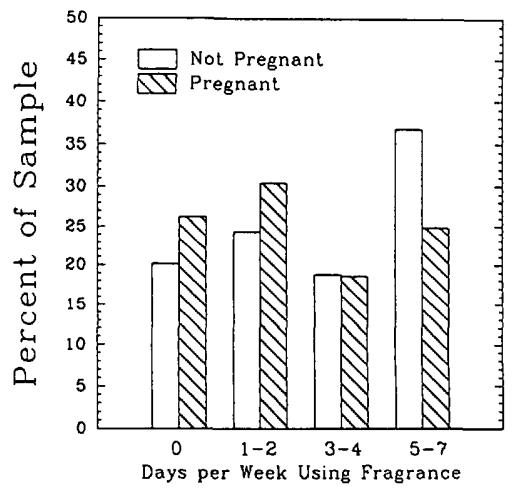

Fig. 3. Distribution of pregnant and nonpregnant women across four frequency categories of fragrance use.

TABLE 4. Pregnancy Status and Odor-Evoked Memory $^{\circ}$

\begin{tabular}{lcc}
\multicolumn{1}{c}{ Odor } & Nonpregnant & Pregnant \\
\hline Androstenone & 27.9 & $25.0^{\star}$ \\
Isoamyl acetate & 57.0 & $55.1^{\star}$ \\
Galaxolide & 29.0 & $25.5^{\star}$ \\
Eugenol & 70.4 & $69.1^{\star *}$ \\
Mercaptans & 46.4 & $44.2^{\star}$ \\
Rose & 66.6 & $64.2^{\star}$ \\
\hline
\end{tabular}

${ }^{a}$ Values are the percentage of each group reporting a memory.

* Chi-square test (performed on frequencies), $p<$ 0.00001 .

* Chi-square test (performed on frequencies), $p<$ 0.01 . 


\section{A. N. GILBERT AND C. I. WYSOCKI}

TABLE 5. Pregnancy Status and Self-Ratings of Olfactory Ability

\begin{tabular}{rcc}
\hline \multicolumn{1}{c}{ Self-Rating } & Nonpregnant & Pregnant \\
\hline Excellent $=5$ & 32.3 & 30.6 \\
4 & 45.6 & 47.9 \\
3 & 19.2 & 19.1 \\
2 & 2.3 & 1.8 \\
Poor $=1$ & 0.6 & 0.6 \\
\hline
\end{tabular}

${ }^{a}$ Chi-square $=40.13, p<0.00001$.

egory 4; Table 5). Lower self-assessments were unlikely to be due to hypochondriasis, or to greater attentiveness to somatic complaints, given that fewer pregnant women reported allergies (to pollen, drugs, or foods) and illnesses (arthritis, ulcer, hypertension) (Table 6). More pregnant than nonpregnant women reported never having lost their sense of smell $(23.0 \%$ vs. $19.9 \%)$. While $3.1 \%$ of nonpregnant women had discussed their sense of smell with a physician, only $2.5 \%$ of pregnant women had done so. Pregnant women were also less likely to smoke tobacco $(7.9 \%$ vs. $17.5 \%)$. This $55 \%$ decrease corresponds well to the estimate that $58 \%$ of women either quit or markedly decrease smoking once they become pregnant (9). Whether reduced smoking is motivated by a pregnancy-related change in sensory experience, or by health concerns, remains an open question.

\section{GENERAL DISCUSSION}

The existence of pregnancy-related hyposmia and hyperosmia has been the object of much conjecture. Zwaardemaker (10), in his classic treatise on olfaction, reiterated the long-standing belief that pregnancy is associated with hyperacuity, especially in the first months. Yet he also noted that "to date, olfactometric determinations are lacking." The hypothesis of pregnancy-related hyperosmia received some support in investigations based on very small samples of pregnant women $(11,12)$. When an objective psychophysical study of odor perception in pregnancy was finally performed, the results were at odds with Zwaardemaker's traditional view-there was no indication of hyperacuity. Repeated peri-partum observations of 22 women revealed that olfactory sensitivity decreased in late pregnancy and rebounded following delivery (8). This finding is consistent with other clinical $(13,14)$ and anecdotal reports of transient, pregnancy-related hyposmia. Doty (15) reviewed the few available studies on olfactory sensitivity during pregnancy. Although the results are often contradictory, he concluded that sensitivity during late pregnancy is lower than normal. He also concluded that anecdotal reports of pregnancy-related hypersensitivity, although they cannot be ruled out, have received little support in the literature (16).

Profet (2) has proposed that pregnancy sickness (i.e., food aversions, nausea, and

TABLE 6. Pregnancy Status and Disease Diagnosis $^{a}$

\begin{tabular}{lcc}
\hline \multicolumn{1}{c}{ Disease } & Nonpregnant & Pregnant \\
\hline Arthritis & 5.4 & $2.9^{\star}$ \\
Ulcer & 4.2 & $3.0^{\star}$ \\
Hypertension & 3.6 & $2.0^{\star}$ \\
Diabetes & 1.0 & 0.9 \\
Allergy & & \\
$\quad$ Pollen & 25.2 & $22.3^{\star}$ \\
Drugs & 15.0 & $13.1^{*}$ \\
Foods & 9.7 & $7.7^{\star}$ \\
Animals & 13.3 & 12.8 \\
\hline
\end{tabular}

"Values are percentage of group reporting the diagnosis.

* Chi-square, $p<0.00001$. 


\section{OLFACTION IN PREGNANCY}

vomiting) is not a pathology, but an evolutionary adaptation to protect the embryo against maternal ingestion of teratogens and abortifacients. Profet notes that bitter tastes and pungent odors are often signals of evolved toxic defenses in plants. While these can be detoxified or processed without harm in the adult, they are harmful in even small amounts to the embryo. Changes in olfactory perception that increase rejection of bitter tastes and pungent odors would act as a mechanism to increase maternal avoidance of toxins. Profet reports that pregnancy sickness occurs early in pregnancy (after implantation and during organogenesis), just when the embryo is most vulnerable to maternally ingested toxins.

The Smell Survey did not distinguish between first, second, and later pregnancies, nor did it identify gestational stage. Nevertheless, one set of results is consistent with Profet's hypothesis that highly flavored and odorous items are avoided in pregnancy. The pungent, spicy, clovelike odor of eugenol was more frequently detected by pregnant women, who more frequently identified it as spicy, and who found it less pleasant, edible, and wearable.

The most frequent differences between pregnant and nonpregnant women were in their response to the musky/urinous smell of androstenone. Pregnant women found it less intense, and were less able to describe it correctly; they also found it more pleasant, and were more willing to eat it or wear it.

Future experimental work might test Profet's hypothesis that change in olfactory experience is most pronounced in the first trimester, perhaps by assessing odor perception in each trimester. It would also be worthwhile to compare first and later pregnancies, as clinical reports indicate a clustering of olfactory symptoms $(8,10)$ and food cravings and nausea $(17,18)$ in the former.

In summary, the Smell Survey results provide quantitative evidence for pregnancy-related changes in the perception of odors, and in odor-related behavior during pregnancy. Despite a poorer selfassessment of their smell ability, pregnant women showed odor detection ability and odor intensity perception very similar to that of nonpregnant women. The evidence also suggests that pregnant women were more likely to experience odors as less pleasant, and to find them less edible. Pregnancy was associated with a marked reduction in the frequency of perfume use.

The authors thank Dr. Cynthia Hedricks for her comments on the manuscript.

\section{REFERENCES}

1. Taggart N: Food habits in pregnancy. Proc Nutr Soc 20:35-40, 1961

2. Profet M: Pregnancy sickness as adaptation: A deterrent to maternal ingestion of teratogens. In Barkow J, Cosmides L, Tooby J (eds). The Adapted Mind: Evolutionary Psychology and the Generation of Culture. London, Oxford University Press, 1991

3. Gilbert AN, Wysocki CJ: The Smell Survey results. National Geographic 172:514-525, 1987

4. Wysocki CJ, Gilbert AN: The National Geographic Smell Survey: The effects of age are heterogenous. In Murphy C, Cain WS, Hegsted DM (eds), Nutrition and the Chemical Senses in Aging: Recent Advances and Current Research Needs. Ann NY Acad Sci 561:12-28, 1989 


\section{A. N. GILBERT AND C. J. WYSOCKI}

5. Albone ES: Mammalian Semiochemistry-The Investigation of Chemical Signals Between Mammals. Chichester, Wiley, 1984, 85-86

6. Wysocki CJ, Beauchamp GK: Ability to smell androstenone is genetically determined. Proc Natl Acad Sci USA 81:4899-4902, 1984

7. Brown JE, Toma RB: Taste changes during pregnancy. Am J Clin Nutr 43:414-418, 1986

8. Hansen R, Glass L: Über den Geruchssinn in der Schwangerschaft. Klin Wochenschr 15:891-894, 1936

9. Killam AP: Tobacco smoking. In Gleicher N (ed), Principles of Medical Therapy in Pregnancy. New York, Plenum, 1985, 114-117

10. Zwaardemaker H: Die Physiologie des Geruchs. Leipzig, Engelmann, 1895

11. Elsberg CA, Brewer ED, Levy I: The sense of smell. IV. Concerning conditions which may temporarily alter normal olfactory acuity. Bull Neurologic Inst New York 4:31-34, 1935

12. Henssge E: Steigerung der Geruchsempfindlichkeit in der Schwangerschaft. Psychol Med 4:206-207, 1930

13. Schmidt H: Vorübergehende Anosmie und Ageusie in der Schwangerschaft. Klin Wochenschr 4:19671968,1925

14. Mabry RL: Intranasal steroid injection during pregnancy. South Med ] 73:1176-1179, 1980

15. Doty RL: Reproductive endocrine influences on human nasal chemoreception: A review. In Doty RL (ed), Mammalian Olfaction, Reproductive Processes, and Behavior. New York. Academic Press, 1976, 295-321

16. Doty RL: Gender and endocrine-related influences on human olfactory perception. In Meiselman HL, Rivlin RS (eds), Clinical Measurement of Taste and Smell. New York, Macmillan, 1986, 377-413

17. Trethowan WH. Dickens G: Cravings, aversions and pica of pregnancy. In Howells JG (ed). Modern Perspectives in Psycho-Obstetrics. New York. Brunner/Mazel, 1972, 251-268

18. Hook EB: Dietary cravings and aversions during pregnancy. Am J Clin Nutr 31:1355-1362, 1978 